\title{
A population-based study of syphilis and sexually transmitted disease syndromes in north-western Tanzania. 1. Prevalence and incidence
}

\author{
F Mosha, A Nicoll, L Barongo, M Borgdorff, J Newell, K Senkoro, H Grosskurth, \\ J Changalucha, A Klokke, J Killewo, J Velema, A S Muller, J Rugemalila, R Hayes, \\ D Mabey
}

\begin{abstract}
Objective-To determine the prevalence of syphilis and the prevalence and incidence of self-reported STD syndromes in the population of Mwanza Region, North-Western Tanzania.

Methods-A population-based random cluster sample survey, stratified by rural, roadside or urban residence, of 4173 individuals aged 15-54 years was performed in 1990-91. The seroprevalence of syphilis (using TPHA and RPR) and the prevalence and incidence of self-reported genital ulcer syndrome (GUS) and genital discharge syndrome (GDS) were determined.
\end{abstract}

Results-Active syphilis was detected in $9 \%$ of the adult population, while $15 \%$ had serological evidence of past or current infection. Seroprevalence was significantly lower in the rural than in the roadside and urban populations, but there was little difference between men and women. Amongst men, a history of GDS was reported by $28 \%$, and a history of GUS by $14 \%$, with point prevalences of $2.3 \%$ and $1.3 \%$ respectively. Annual incidences among men were $6.8 \%$ for GDS and $3.6 \%$ for GUS. Women reported these conditions less frequently. There was little difference between the strata in the prevalence or incidence of reported STD syndromes.

Conclusion-Sexually transmitted diseases represent a major public health problem in both the rural and urban populations of Mwanza Region.

(Genitourin Med 1993;69:415-420)

\section{Introduction}

Syphilis and other sexually transmitted diseases (STDs) are highly prevalent in many parts of sub-Saharan Africa, perhaps owing in part to the lack of effective curative services, and are a major cause of morbidity, particularly among women and infants. ${ }^{1-3}$ Because STDs represent only one of many public health problems in developing countries, they have not until recently attracted much attention within or outside the scientific community. In particular, there is little quantitative information on the prevalence and incidence of STDs in the general population, previous reports having been concerned almost exclusively with high risk populations or clinic attenders.
Since the onset of the HIV/AIDS epidemic, STDs have generated much more interest. In Africa HIV is transmitted mostly through heterosexual intercourse, ${ }^{4-6}$ and an association has been observed between HIV infection and other STDs. ${ }^{7-9}$ It has been suggested that this may be a causal association in which STDs directly facilitate the transmission of HIV. ${ }^{1011}$

In Mwanza Region, North-Western Tanzania, a region-wide population survey was performed with four main objectives: to determine the prevalences of HIV infection, syphilis and STD-related syndromes; to identify risk factors for HIV infection and other STDs; to measure the association between HIV infection and other STDs; and to provide data to assist with the planning of a region-wide programme to improve the detection and management of STDs. Detailed data on HIV prevalence and associated risk factors obtained through this crosssectional study have been reported elsewhere. ${ }^{12}$ The present paper reports the prevalence and incidence of syphilis and STD-related syndromes in this region.

\section{Methods}

Mwanza Region is situated on the southern shores of Lake Victoria, and has a population of approximately 2 million. ${ }^{13}$ Mwanza Municipality has a population of about 250,000 , the remainder of the population living in small towns and villages. For the purposes of this study the region was divided into three strata: urban (Mwanza Muncipality), roadside (small towns and villages along the main roads) and rural (all other villages). From each stratum 20 villages (wards in the urban stratum) were selected randomly with probability of selection proportional to population size. Within each chosen village, ten-cell units were selected by simple random sampling from a list of all tencell units in the village to give a total of approximately 50 eligible individuals in each urban or roadside site, and 100 in each rural site, all those aged between 15 and 54 years being eligible. (Ten-cell units are groups of approximately ten households defined by the political structure of Tanzania: every household belongs to a ten-cell unit). The numbers selected for inclusion in the urban, roadside and rural strata were 1554,1157 and 2434 respectively, and of these 1187,962 and 2024 participated, giving coverage rates of $76 \%$, $83 \%$ and $83 \%$. 


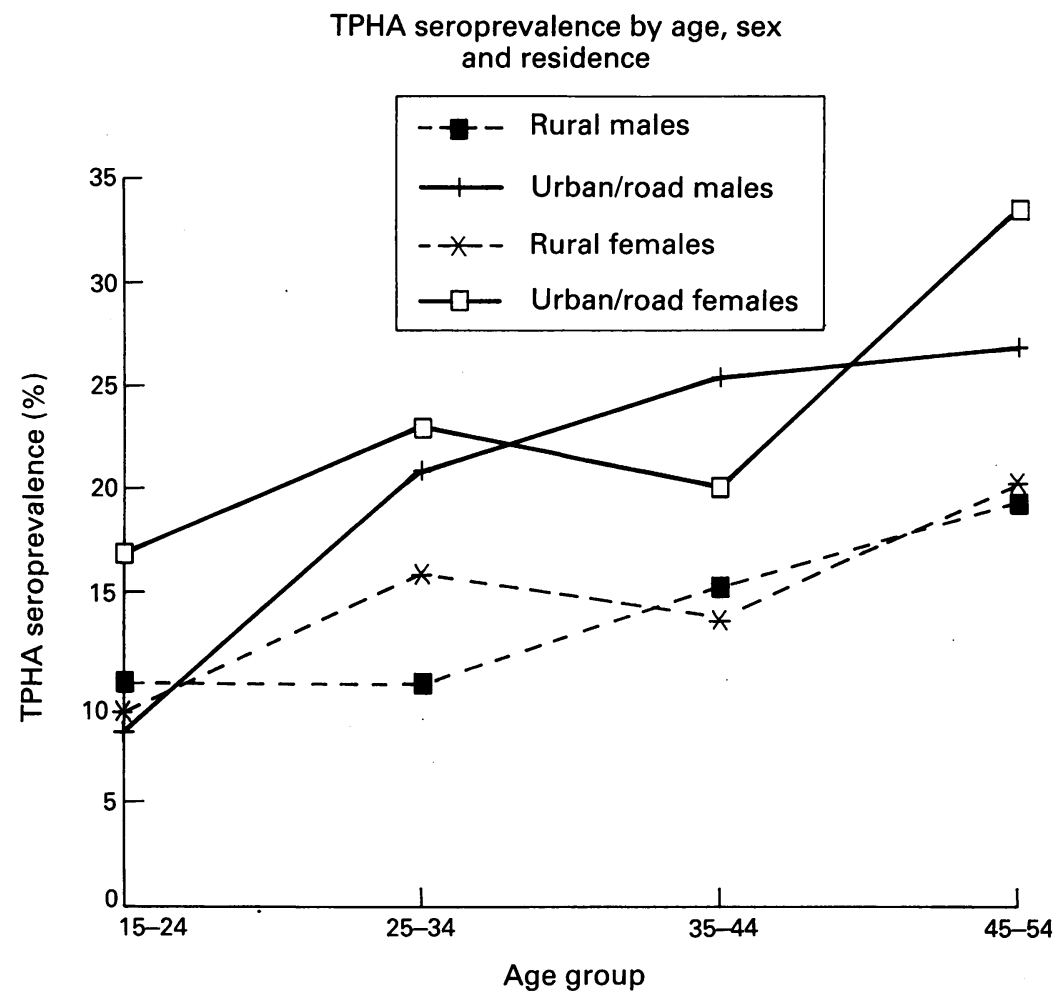

Figure 1 Prevalence of TPHA seropositivity in Mwanza Region by age, sex and residence.

The survey took place between August 1990 and February 1991. In a confidential interview; participants were asked in a local language about their history of STDs and various risk factors, using a structured questionnaire administered by an interviewer of the same sex. The questions concerning genital ulcer syndrome (GUS) were: "Do you at present have an ulcer on your private parts? Have you ever had an ulcer in the past? If so, was this within the past year?" The questions concerning genital discharge syndrome (GDS) were: "Do you at present have any purulent or watery discharge from your private parts (qualified for females by the word "unusual")? Have you ever had this in the past? If so, was this within the past year?" Individuals reporting a current STD were offered a genital examination by a clinician, and were treated according to guidelines issued by the Tanzanian Ministry of Health. Since only a small proportion of all subjects were examined, reliable data on the prevalence of clinically diagnosed STDs were not available from this study, and so this paper focuses on the occurrence of reported GUS and GDS.

Table 1 Prevalence of serological markers of syphilis in Mwanza Region by residence and sex

\begin{tabular}{|c|c|c|c|c|c|}
\hline & Sex & Rural & Roadside & Urban & Region $\dagger$ \\
\hline Sample size & $M$ & 978 & 434 & 597 & 2009 \\
\hline \multirow{3}{*}{ TPHA + /RPR + } & $F$ & 1046 & & 590 & 2164 \\
\hline & $\mathbf{M}$ & $7 \cdot 0^{\star}$ & $12 \cdot 3$ & $9 \cdot 3$ & $8 \cdot 1$ \\
\hline & $\mathbf{F}$ & & & $12 \cdot 4$ & $\begin{array}{l}(0.0-11 \cdot 1) \\
9 \cdot 4\end{array}$ \\
\hline \multirow{3}{*}{ TPHA +} & & $(6 \cdot 0-10 \cdot 4)$ & $(10 \cdot 0-17 \cdot 5)$ & $(8 \cdot 4-18 \cdot 2)$ & $(6 \cdot 7-13 \cdot 1)$ \\
\hline & $\mathbf{M}$ & $\begin{array}{l}13 \cdot 1 \\
(9 \cdot 4-18 \cdot 4)\end{array}$ & $\begin{array}{l}22 \cdot 4 \\
(17 \cdot 8-28 \cdot 2)\end{array}$ & $\begin{array}{l}15 \cdot 9 \\
(11 \cdot 9-21 \cdot 3)\end{array}$ & $\begin{array}{l}14 \cdot 9 \\
(12 \cdot 1-18 \cdot 3)\end{array}$ \\
\hline & $\mathbf{F}$ & $\begin{array}{l}13 \cdot 5 \\
(10 \cdot 2-17 \cdot 7)\end{array}$ & $\begin{array}{l}21 \cdot 7 \\
(18 \cdot 1-25 \cdot 9)\end{array}$ & $\begin{array}{l}20 \cdot 5 \\
(16 \cdot 1-26 \cdot 1)\end{array}$ & $\begin{array}{l}15 \cdot 8 \\
(12 \cdot 9-19 \cdot 3)\end{array}$ \\
\hline
\end{tabular}
$\star \%$ prevalence $(95 \%$ confidence interval) calculated with allowance for cluster sampling
scheme.

†Regional estimates obtained by weighting according to stratum populations.
After interview, a sample of venous blood was taken from all consenting subjects, and a rapid plasma reagin test (RPR, Wellcome, VD-25) was performed on the spot, subjects with positive tests being treated according to national guidelines. Aliquots of sera were sent for laboratory testing with RPR and TPHA (Treponema Pallidum Haemagglutination Assay, Fujirebio). A positive result for both TPHA and RPR was regarded as an indicator of active syphilis. A positive TPHA result combined with a negative $R P R$ result was interpreted as indicating a history of successfully treated syphilis. Quality control serology was carried out internally, as well as at the zonal teaching hospital and the London School of Hygiene and Tropical Medicine.

Results calculated included the prevalence, cumulative incidence and annual incidence of STD syndromes and syphilis by sex and stratum, and their $95 \%$ confidence intervals, adjusted to take account of cluster sampling ${ }^{14}$; and the estimated prevalence and incidence for the whole region, based on population data from the Tanzanian census of $1988,{ }^{13}$ extrapolated to 1990 using estimates of growth rates from the same publication, and assuming roadside and urban growth rates were equal. The phrase cumulative incidence is used to denote the proportion of people who have ever been affected, including those affected at the time of the survey.

\section{Results}

Response rates of $76 \%, 83 \%$ and $83 \%$ were attained in the urban, roadside and rural strata respectively, giving an overall response rate of $81 \%$.

\section{SYPHILIS}

Overall prevalences of TPHA positivity, indicating past or current syphilis, were $14.9 \%$ for men and $15.8 \%$ for women (table 1 ). Of these, $54 \%$ and $59 \%$ respectively had active syphilis (TPHA +, RPR +), giving prevalence estimates for the population of $8 \cdot 1 \%$ and $9 \cdot 4 \%$ respectively. There were no significant differences in the prevalence of either active syphilis or TPHA positivity between the urban and roadside strata, but prevalences in the rural stratum were significantly lower than those in the urban and roadside strata combined ( $\mathrm{p}<0.001$ in each case).

As expected, TPHA positivity increased significantly with age in both rural and urban/roadside strata and in both sexes $\left(\chi^{2}\right.$ test-for-trend gives $\mathrm{p}<0.005$ in all four groups; see fig 1). The highest rates were observed in the age group 45-54 years, ranging from $20 \%$ for men in rural villages to $34 \%$ for women in urban and roadside settlements. Active syphilis showed less age-related variation, and only in urban/roadside males was a significant upward trend observed $\left(\chi^{2}\right.$ test-for-trend gives $\mathrm{p}<0.001$; in other three groups $\mathrm{p}>0.2$; see fig 2 ).

Many infections are acquired at a young age, particularly among women in the urban and roadside strata (fig 1). Moreover, the prevalences of both active and treated syphilis 


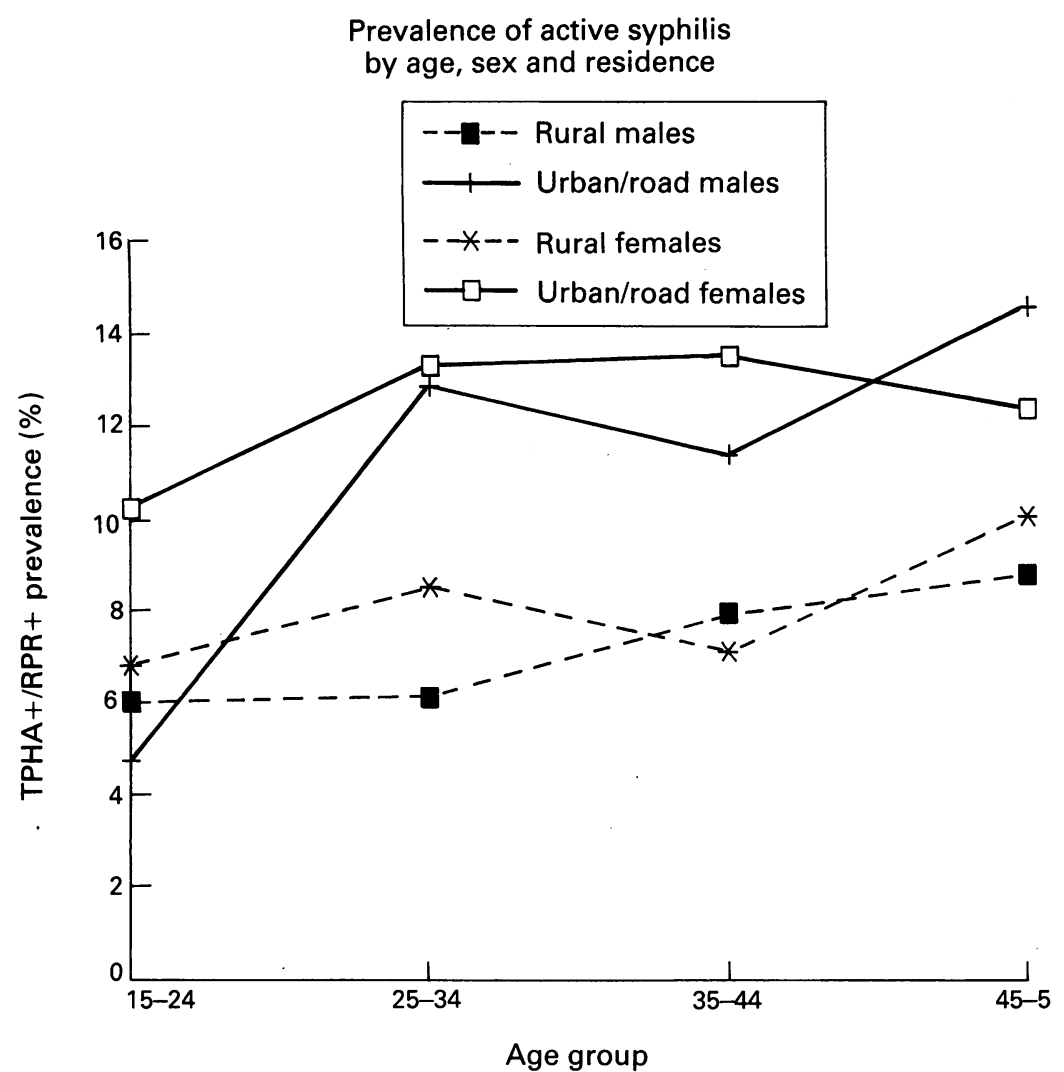

Figure 2 Prevalence of active syphilis in Mwanza Region by age, sex and residence.

among 15-24 year old women in these areas were more than double those in men of the same age group: for example, $10 \%$ of women aged 15-24 years were positive by both RPR and TPHA compared with $5 \%$ of men $(p=$ $0.004)$. Other than in this age/residence group, syphilis seroprevalences showed little difference between the sexes.

Table 2 Prevalence and incidence of reported genital ulcer syndrome (GUS) and genital discharge syndrome (GDS) in Mwanza Region by residence stratum and sex. See table 1 for sample sizes

\begin{tabular}{|c|c|c|c|c|c|}
\hline & Sex & Rural & Roadside & Urban & Regiont \\
\hline \multicolumn{6}{|l|}{ GUS } \\
\hline \multirow{3}{*}{$\begin{array}{l}\text { Cumulative } \\
\text { incidence }\end{array}$} & $\mathbf{M}$ & $14 \cdot 1^{\star}$ & $14 \cdot 6$ & $15 \cdot 6$ & $14 \cdot 4$ \\
\hline & $F$ & $\begin{array}{c}(11 \cdot 1-17 \cdot 9) \\
4 \cdot 3\end{array}$ & $\begin{array}{l}(10 \cdot 6-20 \cdot 0) \\
5 \cdot 4\end{array}$ & $\begin{array}{c}(11 \cdot 5-21 \cdot 0) \\
2 \cdot 4\end{array}$ & $\begin{array}{c}(11 \cdot 6-17 \cdot 8) \\
4 \cdot 2\end{array}$ \\
\hline & & $(2 \cdot 9-6 \cdot 2)$ & $(3 \cdot 7-8 \cdot 0)$ & $(1 \cdot 2-4 \cdot 9)$ & $(2 \cdot 7-6 \cdot 5)$ \\
\hline \multirow{3}{*}{$\begin{array}{l}\text { Annual } \\
\text { incidence }\end{array}$} & $\mathbf{M}$ & 3.8 & 3.0 & 3.3 & $3 \cdot 6$ \\
\hline & $F$ & $(2 \cdot 6-5 \cdot 4)$ & $(1 \cdot 6-5 \cdot 7)$ & $(1 \cdot 7-6 \cdot 3)$ & $(2 \cdot 0-6 \cdot 4)$ \\
\hline & $F$ & $(1 \cdot 1-3 \cdot 4)$ & $(1.7-4.8)$ & $(0 \cdot 8-4 \cdot 4)$ & $(0.8-4.9)$ \\
\hline \multirow{2}{*}{$\begin{array}{l}\text { Point } \\
\text { prevalence }\end{array}$} & $M$ & 1.7 & 0.3 & 0.2 & 1.3 \\
\hline & F & $\begin{array}{c}(1 \cdot 0-3 \cdot 0) \\
0 \cdot 4 \\
(0 \cdot 2-1 \cdot 2)\end{array}$ & $\begin{array}{c}(0.0-1 \cdot 9) \\
0 \cdot 9 \\
(0.3-2 \cdot 2)\end{array}$ & $\begin{array}{l}(0.0-0.8) \\
1.0 \\
(0.2-4.0)\end{array}$ & $\begin{array}{l}(0 \cdot 7-2 \cdot 3) \\
0 \cdot 6 \\
(0 \cdot 0-10 \cdot 6)\end{array}$ \\
\hline \multirow{3}{*}{$\begin{array}{l}\text { GDS } \\
\text { Cumulative } \\
\text { incidence }\end{array}$} & & & & & \\
\hline & $\mathbf{M}$ & $\begin{array}{l}27 \cdot 3 \\
(21 \cdot 6-34 \cdot 5)\end{array}$ & $\begin{array}{l}28 \cdot 6 \\
(22 \cdot 7-36 \cdot 0)\end{array}$ & $\begin{array}{l}30 \cdot 8 \\
(25 \cdot 0-38 \cdot 0)\end{array}$ & $\begin{array}{l}28 \cdot 0 \\
(24 \cdot 6-31 \cdot 9)\end{array}$ \\
\hline & F & $\begin{array}{l}8 \cdot 0 \\
(6 \cdot 0-10 \cdot 6)\end{array}$ & $5 \cdot 3$ & $4 \cdot 4$ & $7 \cdot 1$ \\
\hline \multirow{2}{*}{$\begin{array}{l}\text { Annual } \\
\text { incidence }\end{array}$} & $M$ & $\begin{array}{l}6.7 \\
(4 \cdot 6-9 \cdot 8)\end{array}$ & 6.3 & 7.5 & 6.8 \\
\hline & F & $\begin{array}{l}4.8 \\
(3.3-7 \cdot 0)\end{array}$ & $\begin{array}{l}3.5 \\
(2 \cdot 1-5 \cdot 7)\end{array}$ & 3.5 & $4 \cdot 4$ \\
\hline \multirow{2}{*}{$\begin{array}{l}\text { Point } \\
\text { prevalence }\end{array}$} & $M$ & 2.6 & $2 \cdot 1$ & $1 \cdot 0$ & 2.3 \\
\hline & F & $\begin{array}{c}(1 \cdot 6-4 \cdot 3) \\
2 \cdot 1 \\
(1 \cdot 1-3 \cdot 9)\end{array}$ & $\begin{array}{c}(0 \cdot 9-5 \cdot 0) \\
1 \cdot 4 \\
(0 \cdot 7-2 \cdot 8)\end{array}$ & $\begin{array}{l}(0.5-2 \cdot 0) \\
1 \cdot 0 \\
(0 \cdot 4-2 \cdot 4)\end{array}$ & $\begin{array}{c}(1 \cdot 4-3 \cdot 8) \\
1 \cdot 8 \\
(0 \cdot 9-3 \cdot 8)\end{array}$ \\
\hline \multirow{3}{*}{$\begin{array}{l}\text { GUS and/or GDS } \\
\text { Annual } \\
\text { incidence }\end{array}$} & $\mathbf{M}$ & $10 \cdot 0$ & & & \\
\hline & $\mathbf{F}$ & $\begin{array}{l}(7 \cdot 4-13 \cdot 2) \\
5 \cdot 7\end{array}$ & $\begin{array}{l}(5 \cdot 8-12 \cdot 7) \\
5 \cdot 0\end{array}$ & $\begin{array}{l}(6 \cdot 9-13 \cdot 4) \\
4 \cdot 8\end{array}$ & $(7 \cdot 5-12 \cdot 6)$ \\
\hline & & $(3 \cdot 9-8 \cdot 2)$ & $(3 \cdot 2-7 \cdot 8)$ & $(3 \cdot 1-7 \cdot 4)$ & $(3 \cdot 8-8 \cdot 0)$ \\
\hline
\end{tabular}

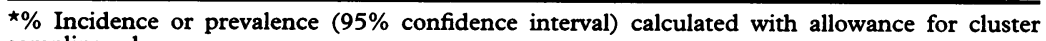
sampling scheme.

†Regional estimates obtained by weighting according to stratum populations.
GENITAL ULCER SYNDROME (GUS) AND GENITAL DISCHARGE SYNDROME (GDS) Cumulative incidence

Of men $14 \cdot 4 \%$ and of women $4 \cdot 2 \%$ reported ever having a genital ulcer. The corresponding proportions for urethral discharge or abnormal vaginal discharge were $28.0 \%$ and $7 \cdot 1 \%$ respectively (table 2 ). This pattern of a history of GDS being roughly twice as common as a history of GUS could be seen within each stratum for either sex, with the exception of women in roadside settlements who showed an almost identical proportion reporting each syndrome. Little difference could be observed between the three strata for either syndrome. Overall the reported cumulative incidences among men were three to four times higher than among women.

\section{Point prevalence}

Reported point prevalences for GUS at the time when the interview was conducted were $1.3 \%$ for men and $0.6 \%$ for women (table 2 ). For GDS the prevalences were $2 \cdot 3 \%$ and $1 \cdot 8 \%$ respectively.

For either sex reported point prevalences were higher in rural villages than in roadside settlements or urban wards, with one exception: genital ulcers were reported more commonly among women in urban and roadside settlements than in rural villages. However, absolute figures for point prevalences were small, with widely overlapping confidence intervals, and none of the stratum differences were statistically significant.

All individuals reporting a current STD syndrome were offered examination and treatment. Some discrepancies between reported and observed STD syndromes were noted: some individuals reported an ulcer as a genital discharge and vice versa, some were found not to have STD-related symptoms at all, and a few, who at first had not reported STD symptoms during the interview, only mentioned such symptoms at the treatment unit when referred there with other ailments. It was not possible to examine all the individuals who reported a current STD syndrome. Genital ulcers were found to be present in five of 10 males reporting this syndrome who were examined $(50 \%)$, and in only one of five females $(20 \%)$. Urethral discharge was confirmed at examination in 17 of 27 males reporting this syndrome $(63 \%)$, and abnormal vaginal discharge in seven of 13 females (54\%). Field conditions in this survey may, however, have compromised the reliability of the clinical examination.

\section{Annual incidence}

Annual incidence rates were estimated as the proportion of adults reporting at least one episode of GUS or GDS during the past year, ignoring multiple episodes. Separate rates for GUS and GDS are given in table 2; the variation with age of their combined incidence is shown in fig 3. Overall incidences of GUS were $3.6 \%$ in men and $2.0 \%$ in women, and those of GDS $6.8 \%$ and $4.4 \%$ respectively, again twice those of GUS. The combined 
Incidence of GUS and/or GDS during past year by age, sex and residence

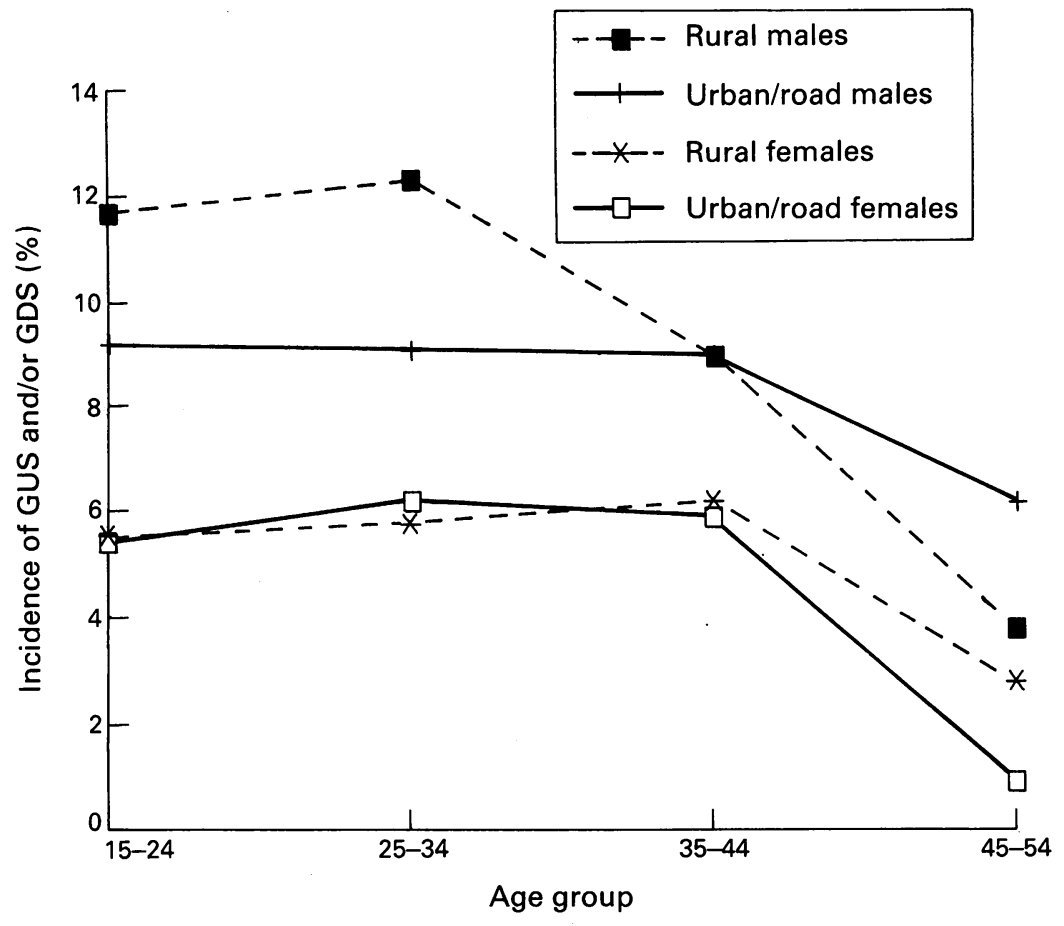

Figure 3 Proportion reporting genital ulcer syndrome (GUS) andlor genital discharge syndrome (GDS) during the past year by age, sex and residence.

annual incidences of GUS and/or GDS were high. In the two age groups from 15 to 34 years, incidences among men were $12 \%$ in rural villages and $9 \%$ in the other two strata; and among women roughly $6 \%$ in each stratum (fig 3). The combined incidence remained high in the 35-44 years age group. Incidences for the oldest age group investigated (45-54 years) were much lower, ranging from $1 \%$ to $6 \%$ depending on sex and stratum. Significant downward trends in combined incidence with increasing age were found in rural males $\left(\chi^{2}\right.$ test-for-trend gives $p=0.006)$ and roadside females $(p=0.02)$.

\section{Duration}

Using the approximate relationship point prevalence $=$ incidence $\times$ duration, the average duration of STD syndromes in our study population could be roughly estimated. For GDS, calculated average durations varied between 4.0 and 5.2 months for both sexes in roadside settlements and rural villages, while in town average duration was only 1.6 months in men and 3.4 months in women. For GUS, absolute numbers were small; over all strata, calculated durations were 4.3 months for males and 3.6 months for females.

Table 3 Reported genital ulcer syndrome (GUS) and genital discharge syndrome (GDS) during the past year among males and females in Mwanza Region

\begin{tabular}{|c|c|c|c|c|c|c|}
\hline & \multicolumn{3}{|l|}{ Males } & \multicolumn{3}{|l|}{ Females } \\
\hline & $G D S+$ & GDS- & Total & $G D S+$ & $G D S-$ & Total \\
\hline $\begin{array}{l}\text { GUS + } \\
\text { GUS - } \\
\text { Total }\end{array}$ & $\begin{array}{l}17(24 \%)^{\star} \\
118(6 \%) \\
135\end{array}$ & $\begin{array}{r}53 \\
1821 \\
1874\end{array}$ & $\begin{array}{r}70 \\
1939 \\
2009\end{array}$ & $\begin{array}{l}21(45 \%) \\
69(3 \%) \\
90\end{array}$ & $\begin{array}{r}26 \\
2048 \\
2074\end{array}$ & $\begin{array}{r}47 \\
2117 \\
2164\end{array}$ \\
\hline
\end{tabular}

$\star \%$ reporting GDS.
ASSOCIATIONS BETWEEN SYNDROMES AND WITH SEROLOGY

Table 3 shows the association between reported GUS and GDS during the past year in males and females. There was a clear association between the two syndromes in both sexes (Mantel-Haenszel $\chi^{2}$ allowing for age gives $\mathrm{p}<0.001$ for each sex). Despite their association, each syndrome was reported alone more often than with the other syndrome. Similar findings were obtained for the cumulative incidences of the two syndromes.

Among males, the prevalence of active syphilis was $6.9 \%$ in those who reported never having a genital ulcer, $17 \cdot 2 \%$ among those who reported having an ulcer more than one year ago, and $26 \%$ among those who had had an ulcer in the past year, a significant trend $\left(\chi^{2}\right.$ test-for-trend gives $\mathrm{p}<0.001)$. Among females the corresponding prevalences were $9.4 \%, 30.0 \%$ and $21.9 \%$ $(p=0.005) .27 \%$ of males, but only $7 \%$ of females with a positive TPHA test reported having had a genital ulcer at some time.

\section{Discussion}

SYPHIIIS

The interpretation of serological tests for syphilis is difficult. Positive results could be due to non-venereal treponematoses. ${ }^{15}$ However, non-venereal syphilis and yaws have not been reported in Mwanza Region in recent times, and clinical examinations carried out during the survey did not reveal evidence of these diseases. Furthermore, false-positive results can occur with reagin (RPR) tests, due for example to concurrent malaria. This could lead to an over-estimation of active syphilis and to an under-estimation of treated syphilis, although the overall prevalence of active or past syphilis would be unaffected provided the TPHA results are accurate.

The high prevalence of active syphilis in our study corresponds well with reports from other African countries where prevalences among antenatal clinic attenders have ranged from 2.0 to $16.9 \% .^{1}$ Few previous population-based studies have been carried out among rural African populations; in The Gambia, $7 \cdot 2 \%$ of pregnant women in a rural area had active syphilis, ${ }^{15}$ and in a rural Somalian population $7 \%$ of males and $22.5 \%$ of females were infected. ${ }^{1}$ A prevalence of active and treated syphilis together of $33.3 \%$ was found among hospital outpatients in Swaziland. ${ }^{16}$ Sample sizes in these reports usually do not exceed a few hundred. To our knowledge the present study is the first population-based investigation of syphilis seroprevalence in Africa with a sample size of more than 4000 individuals.

In Tanzania, previous surveys revealed a prevalence of active syphilis of $3.9 \%$ in a general outpatient group at a hospital in Dar es Salaam, ${ }^{17}$ which is roughly half the rate found in our study. However, the prevalence of TPHA positivity alone was $16 \cdot 5 \%$ and thus similar to the results of the present study. In another regional centre of Tanzania active 
syphilis was found in $16 \cdot 4 \%$ of outpatients. ${ }^{18}$

In our population-based study, the $12 \%$ prevalence of active syphilis among women in Mwanza town was somewhat higher than the 6-9\% prevalence recorded in a sentinel survey of urban antenatal clinic attenders during the same period. ${ }^{19}$ This accords with data on HIV prevalence, which was also higher among women in the population survey than in antenatal clinic attenders.

In Mwanza Region, active syphilis seems to be more prevalent than the treated infection. Possible explanations could be that the availability or effectiveness of medical services is insufficient, that the incidence of treponemal infection has recently increased, that a group of individuals practising high risk behaviour are being frequently reinfected, or that there are false-positive RPR test results.

It is likely that the residents of urban and roadside areas have easier access to effective treatment than those in rural areas, and therefore that the duration of untreated syphilis would be shorter. The higher seroprevalences found in urban and roadside populations (table 1) therefore suggest a substantially higher incidence of syphilis in these strata than in the rural villages.

The high prevalence of syphilis recorded in this study indicates a substantial public health problem, but the infection level in young women in urban and roadside strata (Figs 1 and 2) is of particular concern: not only can infected mothers pass the infection to their offspring during pregnancy, possibly resulting in stillbirths or diseased children, but also the risk behaviour thus revealed may expose them to HIV infection. In fact a high HIV infection prevalence has been found in young urban women during this survey (16\% in the $15-24$ age group). ${ }^{12}$

\section{STD SYNDROMES}

We suggest that the term genital ulcer syndrome (GUS) is preferable to genital ulcer disease (GUD), since a variety of pathogens can cause genital ulcers, and it is often not possible to diagnose the causative agent on the basis of clinical criteria. ${ }^{20} \mathrm{We}$ use the term genital discharge syndrome (GDS) for the same reasons. For technical reasons the aetiology of GDS and GUS could not be determined in our study.

Prevalences and incidences of STD syndromes have rarely been measured in Africa. The incidence of gonorrhoea has been estimated from hospital records in Swaziland and in Uganda, using the hospital catchment population as denominator; incidences were estimated to be $3 \%$ and $10 \%$ per annum respectively. ${ }^{121}$ Such hospital based studies are likely to underestimate the incidence, since many patients with STDs are not treated in the official health sector. The prevalence of gonorrhoea among antenatal clinic attenders has been found to range from $2 \cdot 1 \%$ to $40 \%$ in various African populations, and of chlamydial infection from $1.3 \%$ to $29 \% .{ }^{1}$ A population-based study in rural Uganda found the prevalence of gonorrhoea to be $18.3 \%$ among women and $8.9 \%$ among men. Significantly, one third of infected males and almost half of infected women did not complain of symptoms. ${ }^{22}$

Little information is available on the incidence of GUS, although it is generally believed to be high since many African clinics see comparable numbers of cases of GUS and GDS. ${ }^{23}$ Prevalence studies have been conducted mainly in high risk populations. ${ }^{24}$

In the present study, all three parameters investigated (lifetime history of the respective condition, incidence during the past year, and point prevalence) were much higher in men than in women for both syndromes (table 2). This contrasts with the findings for syphilis, for which seroprevalences in men and women were almost identical (table 1). The annual incidence of STD syndromes does not differ greatly from the cumulative incidence among women (ratio approximately $2: 1$ ), whereas in men the ratio is approximately $4: 1$; this suggests that a relatively small sub-group of women acquire these conditions over a lifetime of sexual activity, whereas a larger proportion of men do so. However, data on genital symptoms reported by women should be interpreted with caution, since women may not always discover intravaginal or cervical ulcers, and may not be sure whether a genital discharge is abnormal or physiological.

The annual incidences reported for GUS and GDS (table 2, fig 3) are minimum estimates as interviewees were not asked whether any reported syndrome had occurred more than once during the past year. However, a questionnaire designed to elucidate this information is unlikely to have provided more accurate information on incidence, as it would be extremely difficult to distinguish between true reinfections and inadequately treated infections. A more accurate picture of incidence will be obtained from a study which is presently being conducted in a cohort of 1,200 men who are seen at quarterly intervals in the same area.

The duration of GDS will depend on the availability of effective treatment. Untreated GDS may lead to a number of serious complications. It is therefore rather surprising that during the survey only very few cases of epididymitis, orchitis and other complications were seen.

True durations may be somewhat shorter than those calculated here if, because of underreporting and multiple episodes, incidences are too low (assuming that point prevalences are fairly accurate).

In order to plan effective STD control programmes in developing countries it is necessary to estimate the incidence of common STD syndromes so that requirements for drugs and trained personnel can be calculated. This is commonly done by counting the number of reported cases seen in government health facilities. In Mwanza Region, and probably in most developing countries, the figure arrived at by this means is an underestimate of the true incidence. During 1991 we undertook a survey of all 18 rural 
health centres and of 32 rural dispensaries in Mwanza Region, in which we inspected their records for the previous three months to see how many STD patients had been treated on average per month. We estimated from these records that 33,500 patients were treated per year for GDS in rural health facilities, which represent the only official source of health care for the rural population, and that 13,000 were treated for GUS.

Given an incidence of GDS of $6.7 \%$ in rural men and $4.8 \%$ in rural women, and a total rural population in the 15-54 year age group of 637,000 (14), 21,000 cases of this syndrome would be expected to occur in males and 15,000 in females each year in the rural population of Mwanza Region. Given an incidence of GUS of $3.8 \%$ for males and $1.9 \%$ for females, 12000 cases would be expected in males and 6000 in females. If these estimates are correct, more than $80 \%$ of individuals with STD syndromes are treated in the official sector in rural areas of Mwanza Region. However, the treatment given is often ineffective, and our estimates of average STD duration suggest that treatment is often considerably delayed.

The high prevalence and incidence of STD syndromes in this population are of considerable concern: as with syphilis these syndromes not only place a heavy financial burden on health care systems and patients, but may also greatly increase the risk of HIV transmission. The prevalence of HIV infection in the population studied here was $2.5 \%$ in rural villages, $7 \cdot 3 \%$ in roadside settlements and $11.8 \%$ in Mwanza town. Both syphilis and a history of STD syndromes were associated with HIV positivity. ${ }^{12}$

Urgent measures are needed, in this and similar populations, to reduce the incidence and duration of sexually transmitted infections, both through preventive measures and through improved provision of timely and effective treatment.

We thank the Principal Secretary, Ministry of Health and the Director-General of the National Institute for Medical Research for permission to carry out and publish the results of this study. The support of regional, district, ward and village government and party officials is gratefully acknowledged. We government and party officials is gratefully acknowledged. We are particularly grateful for the support and hospitality of the
people included in the survey. This study was supported by people included in the survey. This study was supported by Development Cooperation, the Overseas Development Development Cooperation, the Overseas Development
Administration of the UK Government and the Wellcome Trust.
1 De Schryver A, Meheus A. Epidemiology of sexually transmitted diseases: the global picture. Bull World Health Organ 1990;68:639-54.

2 Over M, Piot P. HIV infection and sexually transmitted diseases. Forthcoming in: Jamison DT and Mosley WH (eds): Disease Control Priorities in Developing Countries. New York: Oxford University Press for the World Bank.

3 Schulz K, Cates W, O'Masra PR. Pregnancy loss, infant death, and suffering: legacy of syphilis and gonorrhoea in Africa. Genitourin Med 1987;62:320-5.

4 Piot P, Plummer FA, Mhalu FS, Lamboray JL, Chin J, Mann JM. AIDS: an international perspective. Science 1988;239:573-9.

5 Chin J, Mann J. Global surveillance and forecasting of AIDS. Bull World Health Organ 1989;67:1-7.

6 Ryder RW, Piot P. Epidemiology of HIV-1 infection in Africa. Bailliere's Clinical Tropical Medicine and
Ander RW, Piot P. Epidemiology of HIV-1 infection in Communicable Diseases 1988;3:13-29.

7 Pepin J, Plummer FA, Brunham RC, Piot P, Cameron DW, Ronald AR. The interaction of HIV and other sexually transmitted diseases: an opportunity for intervention. $A I D S$ 1989;3:3-9.

8 Simonsen JN, Cameron DW, Gakinya MN, et al. Human immunodeficiency virus infection among men with sexually transmitted diseases-experience from a center in Africa. $N$ Engl f Med 1988;319:274-8.

9 Mertens TE, Hayes RJ, Smith PG. Epidemiological methods to study the interaction between HIV infection and other sexually transmitted diseases. AIDS 1990;4: and other

10 Cameron DW, Simonsen JN, D'Costa LJ, et al. Female to male transmission of human immunodeficiency virus type 1: risk factors for seroconversion in men. Lance 1989;ii:403-7.

11 Plummer FA, Simonsen JN, Cameron DW, et al. Cofactors in male-female transmission of human immunodeficiency virus type 1. F Infect Dis 1991;163: 233-9.

12 Barongo LR, Borgdorff MW, Mosha FF, et al. The epidemiology of HIV-1 infection in urban areas, roadside settlements and rural villages in Mwanza Region, Tanzania. AIDS 1992;6:1521-8.

131988 population census: preliminary report. Bureau of Statistics, Ministry of Finance, Economic Affairs and Planning, Dar es Salaam.

14 Bennett S, Woods AJ, Liyanage WM, Smith DL. A simplified general method for cluster sample surveys of health in developing countries. World Health Stat $Q$ 1991;44:98-105.

15 Mabey DCW. Syphilis in sub-Saharan Africa. African fournal of Sexually Transmitted Diseases. 1986;2:61-4

16 Meheus A, Friedman F, Van Dyck E, Guyver T. Genita infections in prenatal and family planning attendants in Swaziland. East African Medical fournal 1980;57 $212-7$.

17 Urassa WK, Moshi S, Rutahindurwa A, Mbwana J, Mhalu FS. Bacteriological findings among patients attending a referral clinic for STDs in Dar es Salaam Tanzanian Medical fournal 1990;1:15-7.

18 Cooper-Poole B. Prevalence of syphilis in Mbeya, Tanzania-the validity of the VDRL as a screening test. Tanzania-the validity of the VDRL as a scre
East African Medical fournal 1986;63:646-50.

19 National AIDS Control Programme AIDS Surveillance Report No. 5. Epidemiology Unit, NACP, Ministry of Health, Dar es Salaam, 1992

20 Fast MV, D'Costa LJ, Nsanze H, et al. The clinical diagnosis of genital ulcer disease in men in the tropics. Sexually Transmitted Diseases 1984;11:72-6.

21 Meheus A, Ballard R, Dlamini M, Ursi JP, Van Dyck E Piot P. Epidemiology and aetiology of urethritis in Swaziland. Int Epidemiol 1980;9:239-45.

22 Arya OP, Nsanzumuhire H, Taber SR. Clinical, cultural and demographic aspects of gonorrhoea in a community in Uganda. Bull World Health Organ 1973;49:587-95.

23 Mabey DCW, Wall RA, Bello CSS. The aetiology of genital ulceration in The Gambia. Genitourin Med 1987;63: $312-5$.

24 D'Costa LJ, Plummer FA, Bowmer J, et al. Prostitutes are a major reservoir of STDs in Nairobi, Kenya. Sexually Transmitted Diseases 1985;12:64-7. 